Acta Technologica Agriculturae 1

Nitra, Slovaca Universitas Agriculturae Nitriae, 2014, p. 6-12

\title{
EVALUATION OF SELECTION INDICES FOR DROUGHT TOLERANCE IN SOME CHICKPEA (CICER ARIETINUM L.) GENOTYPES
}

\author{
Naser SABAGHNIA, Mohsen JANMOHAMMADI*
}

University of Maragheh, Iran

\begin{abstract}
Drought is one of the major abiotic stresses in agriculture worldwide, which limits crop production. The chickpea cultivation areas of Iran are fourth in the world after India, Pakistan and Turkey while most areas (95\%) are planted in rainfed condition and are grown in rotation with cereals. This investigation was carried out to investigate the effect of drought stress seed yield characteristic in seven genotypes of chickpea. A field experiment with two humidity regimes (stressed and non-stressed) was performed in a randomized complete block design layout with three replicates. The analysis of variance for both potential yield (YP) and stress yield (YS) indicated significant differences among seven chickpea genotypes. Also, significant differences were observed among chickpea genotypes regarding twelve drought tolerance indices. Based on the YP, the genotypes FLIP 03-64C, FLIP 98-106C, Arman and Azad had the highest yield under non-stressed condition, while the genotypes FLIP 98-106C and Azad displayed the highest yield under stressed condition. Therefore, the genotypes FLIP 98-106C and Azad are good candidates for commercial recommendation to farmers in both rainfed and irrigated conditions. The relationships among drought tolerance indices are graphically displayed in a plot of two first principal components analysis. The first and second components justified $95.46 \%$ of the variations between criteria (59.36 and $36.10 \%$ for PC1 and PC2, respectively). The STI, K STI, MP, GMP and PI indices exhibited strong correlation with YP, while YI showed strong correlation with YS; therefore, YS can discriminate drought tolerant genotypes with high grain yield under stress conditions.
\end{abstract}

Keywords: chickpea, drought stress, drought tolerance

Chickpea (Cicer arietinum L.) is one of the most important cool season pulse crops of dry lands in the world. It is produced about 6 million tones from 8.5 million ha cultivated land with a mean seed yield of $700 \mathrm{~kg} \cdot \mathrm{ha}^{-1}$ and about $92 \%$ of the sowing area and $88 \%$ of the production takes place in developing countries (FAO, 2012). Chickpea is produced on 700,000 hectares in Iran and ranks fourth in the world after India, Turkey and Pakistan (FAO, 2012). Due to high protein content, the chickpea is used as a major protein source in most of developing countries. For a wide range of agro-ecological environments, it is also an alternative pulse crop for increasing the diversification of different cropping systems (Zdemur and Karadavut, 2003). Chickpea yield affected by biotic stresses is quite low, and yield is below its potential. The use of chickpea in a cereal-based rotation can break the disease and pest cycle, and increase the productivity of the entire rotation (Ozveren-Yucel et al., 2006).

Drought is one of the most common adverse environments, which limits crop production in arid and semi-arid regions. Drought is usually accompanied by high temperatures, which promote evaportranspiration and hence could accentuate the effects of drought (Toker and Cagirgan, 1998). Productivity of crops in rainfed area in Iran is $42 \%$ of irrigated field, and yield losses due to terminal drought range from $35 \%$ to $50 \%$ (Sabaghpour et al., 2006). Plants adapt to drought conditions either through escape, avoidance, or tolerance mechanisms. Most of chickpea production is done in marginal regions in the spring, and due to lack of rainfall during flowering, podding and seed filling, terminal drought stress is the major environmental stress for reducing chickpea production in Iran (Sabaghpour et al., 2006). Therefore, selection for drought tolerant chickpea genotypes is the most important objective for breeding to drought stress.

Genetic improvement for drought tolerance is involved by the lack of fast, screening tools and the inability to create water stress conditions when a large amount of genotypes are to be evaluated. Achieving a genetic increase in yield performance under stressed conditions has been proved to be a difficult task for plant breeders while progress in yield potential has been much higher in non-stressed conditions (Ramirez and Kelly, 1998; Richards et al., 2002). Loss of yield is the main concern of breeders and they emphasize on yield under stress conditions and have used different procedures to evaluate genetic differences in drought tolerant genotypes. Thus, drought resistance indices, which provide a measure of drought based on loss of yield under stressed conditions, have been used for screening tolerant genotypes (Sio-Se Mardeh et al., 2006). The genotypes yield performance in drought stressed and favourable environments seems to be a common starting point in the identification of traits related to drought resistance and the selection of genotypes for breeding programmes (Clarke et al., 1992).

For evaluation of genotypes for drought resistant characteristic, several indices have been proposed based on mathematical relationships between stressed and nonstressed conditions. The stress susceptibility index (SSI) of Fischer and Maurer (1978), the mean productivity (MP) and tolerance (TOL) of Rosielle and Hamblin (1981), the yield stability index (YSI) of Bouslama and Schapaugh (1984), the superiority index (PI) of Lin and Binns (1988), the stress tolerance index (STI), geometric mean productivity (GMP) 
and harmonic mean (HM) of Fernandez (1992), yield index (YI) of Gavuzzi et al. (1997), and relative reduction (RR) of Sadiki (2006) were proposed to screening drought tolerant genotypes. The objectives of the investigation were to (i) identify drought tolerant chickpea genotype(s) under rainfed conditions in the arid and semi-arid areas, and (ii) study interrelationships among the resistance indices.

\section{Material and methods}

In this study, seven chickpea genotypes, including five new improved genotypes from ICARDA (International Centre for Agricultural Research in the Dry Areas) and two checks cultivars from Iran (Arman and Azad), were used. The improved chickpea genotypes were FLIP 03-71C, FLIP 03-64C, FLIP 98-106C, FLIP 00-40C and FLIP 99-66C. The experimental field was ploughed once in early fall and harrowed twice, one week before planting. The recommended dose of fertilizer ( $30 \mathrm{~kg} \mathrm{~N}$ and $75 \mathrm{~kg} \mathrm{P}_{2} \mathrm{O}_{5}$ ha $^{-1}$ ) was applied in the form of urea and triple superphosphate at the time of seedbed preparation. The experimental design was factorial on the basis of randomized complete block in three replicates. The factors were seven chickpea cultivars and two irrigation regimes, including zero irrigation (rainfed condition that received natural rainfall only) and regular irrigation (receiving natural rainfall plus enough irrigation to fill the root zone profile). Seeds were hand-sown on 17 March 2012 in a $4 \mathrm{~cm}$ depth of soil. Treatment plot size was $4 \times 3 \mathrm{~m}$ or $12 \mathrm{~m}^{2}$ (with harvested area $4 \mathrm{~m}^{2}$ ). In each plot, seeds were sown into 16 rows, at a $25 \mathrm{~cm}$ row-to-row spacing and $8 \mathrm{~cm}$ plant-to-plant spacing. Weeding was done manually. During the irrigations, plots were irrigated up to $70 \%$ of field capacity. All necessary cultural practices and plant protection measures were followed uniformly for all the plots during the entire period of experimentation.

Several statistical parameters of drought tolerance were calculated. The stress susceptibility index (SSI) was calculated according to Fischer and Maurer (1978):

$$
S S I=\left[1-\left(Y_{S} / Y p\right)\right] /[1-(\bar{Y} s / \bar{Y} p)]
$$

where:

$Y_{p}$ - genotype yield in non-stress conditions

$Y_{s}$ - genotype yield in stress conditions

$\bar{Y} s$ - mean yield of all genotypes in stress conditions

$\bar{Y} p$ - mean yield of all genotypes yield in non-stress conditions

The mean productivity $(M P)$ as the average yield of $Y_{s}$ and $Y p$ and tolerance ( $T O L)$ as the yield difference under stress and non-stress conditions of Rosielle and Hamblin (1981) were calculated according to these formulas:

$$
\begin{gathered}
M P=(Y s+Y p) / 2 \\
T O L=(Y p-Y s)
\end{gathered}
$$

The yield stability index (YSI) of Bouslama and Schapaugh (1984) was computed based on this relation:

$$
Y S I=Y s / Y p
$$

The superiority index $(P I)$ of Lin and Binns (1988) was calculated according to the following formula:

$$
P i=\sum_{j=1}^{n} \frac{\left(X_{i j}-M_{j}\right)^{2}}{2 n}
$$

where:

$n \quad$ - the number of environments

$X i j$ - the seed yield of the $i$-th genotype in the $j$-th environment

$M j \quad$ - the yield of the genotype with the maximum yield at the environment $j$

The stress tolerance index $(S T I)$, geometric mean productivity (GMP) and harmonic mean (HM) of Fernandez (1992) are defined as follows:

$$
\begin{gathered}
S T I=(Y p \times Y s) / Y p^{2} \\
G M P=\sqrt{(Y s+Y p)} \\
H M=[2(Y p \times Y s)] /(Y p+Y s)
\end{gathered}
$$

Another drought tolerance index as yield index $(Y I)$ was calculated according to Gavuzzi et al. (1997):

$$
Y I=Y s / \bar{Y} s
$$

Finally, relative reduction $(R R)$ in yield due to stress was computed based on this formula (Sadiki, 2006):

$$
R R=(Y p-Y s) / Y p
$$

The experimental data were statistically analysed for variance using the SAS version 6.12 (SAS, 1996). Differences were compared by Least Significant Difference Test (LSD) at alpha 0.05 .

\section{Results and discussion}

Analysis of variance for both potential yield $(Y P)$ and stress yield (YS) indicated significant differences among seven chickpea genotypes (Table 1). Accordingly, significant differences were observed for chickpea genotypes regarding all drought tolerance indices, including $\mathrm{SSI}, \mathrm{MP}$, TOL, STI, GMP, HM, YI, PI, YSI, RR, K STI and $\mathrm{K}_{2} \mathrm{STI}$ (Table 1). Based on the $Y P$, the genotypes FLIP 03-64C, FLIP 98-106C, Arman and Azad were found the highest yield under irrigated (non-stressed) condition, while the genotypes FLIP 98-106C and Azad displayed the highest amount under stressed condition (Table 2). The low performance genotypes were FLIP 03-71C and FLIP 00-40C under nonstressed condition and the genotypes FLIP 03-64C, FLIP 00-40C, FLIP 99-66C and Arman under stressed condition (Table 2). It is interesting that the genotypes FLIP 98-106C and Azad had high performances in both stressed and non-stressed conditions. Other chickpea genotypes were identified as semi-tolerance or semi-sensitive to drought stress (Table 2). It is rare that one single genotype shows good performance in two different humidity conditions 
Table 1 Analysis of variance for yield performances of chickpea genotypes in non-stressed (YP) and stressed (YS) conditions and twelve drought resistance indices

\begin{tabular}{|c|c|c|c|c|c|c|c|c|}
\hline sov & DF & YP & YS & SSI & MP & TOL & STI & GMP \\
\hline Replication & 2 & $101713.5^{\mathrm{ns}}$ & $19235.6^{\mathrm{ns}}$ & $0.033^{\text {ns }}$ & $52365.9^{*}$ & $32481.1^{\text {ns }}$ & $1.90 \times 10^{-8 *}$ & $43199.2^{*}$ \\
\hline Genotype & 6 & 211066.2 & $41419.5^{* *}$ & $0.194^{* *}$ & $79159.9^{* *}$ & $188312.4^{*}$ & $2.88 \times 10^{-8 * *}$ & $63100.2^{* *}$ \\
\hline Error & 12 & 32087.4 & 4882.6 & 0.034 & 10162.4 & 33303.2 & $3.87 \times 10^{-9}$ & 7120.6 \\
\hline $\mathrm{CV}$ & & 9.89 & 8.46 & 18.49 & 7.64 & 18.52 & 7.74 & 6.93 \\
\hline SOV & DF & HM & YI & PI & YSI & $\mathbf{R R}$ & $\mathrm{K}_{1} \mathrm{STI}$ & $\mathrm{K}_{2} \mathrm{STI}$ \\
\hline Replication & & $35858.0^{*}$ & $0.0283^{*}$ & $9.3 \times 10^{9 *}$ & $0.00011^{\mathrm{ns}}$ & $0.00011^{\mathrm{ns}}$ & $2.02 \times 10^{-7 n s}$ & $1.17 \times 10^{-7 *}$ \\
\hline Genotype & & $56970.9^{* *}$ & $0.0607^{* *}$ & $18.2 \times 109^{* *}$ & $0.02006^{* *}$ & $0.02006^{* *}$ & $3.36 \times 10^{-7 * *}$ & $3.20 \times 10^{-7 * *}$ \\
\hline Error & & 6014.4 & 0.0071 & $2.17 \times 10^{9}$ & 0.00238 & 0.00238 & $6.83 \times 10^{-8}$ & $2.48 \times 10^{-8}$ \\
\hline CV & & 6.88 & 8.44 & 40.97 & 10.51 & 9.10 & 30.40 & 18.61 \\
\hline
\end{tabular}

SOV - source of variation; DF - degrees of freedom; ns - non-significant; ** significant on 0.01 level, * significant on 0.05 level

Table 2 Mean comparison for yield performances of chickpea genotypes in non-stressed (YP) and stressed (YS) conditions and twelve drought resistance indices

\begin{tabular}{|c|c|c|c|c|c|c|c|c|c|c|}
\hline Cultivar & \multicolumn{2}{|c|}{ YP } & \multicolumn{2}{|c|}{ YS } & \multicolumn{2}{|c|}{ SSI } & \multicolumn{2}{|c|}{ MP } & \multicolumn{2}{|c|}{ TOL } \\
\hline FLIP 03-71C & 1436.8 & C & 873.2 & $\mathrm{BC}$ & 0.572 & C & 1155.0 & D & 563.5 & $\mathrm{C}$ \\
\hline FLIP 03-64C & 1922.2 & $A B$ & 709.8 & D & 1.230 & $A$ & 1316.0 & $B C D$ & 1212.4 & A \\
\hline FLIP 98-106C & 2095.3 & A & 1015.2 & A & 1.096 & A & 1555.2 & A & 1080.2 & A \\
\hline FLIP 00-40C & 1515.3 & C & 759.9 & $C D$ & 0.767 & $B C$ & 1137.6 & D & 755.3 & $\mathrm{BC}$ \\
\hline FLIP 99-66C & 1679.4 & $B C$ & 739.8 & D & 0.954 & $A B$ & 1209.6 & $C D$ & 939.6 & $A B$ \\
\hline Arman & 1997.1 & $A B$ & 744.6 & D & 1.271 & A & 1370.9 & $B C$ & 1252.5 & A \\
\hline Azad & 2033.4 & A & 939.5 & $A B$ & 1.110 & A & 1486.4 & $A B$ & 1093.9 & A \\
\hline Cultivar & \multicolumn{2}{|c|}{ STI } & \multicolumn{2}{|c|}{ GMP } & \multicolumn{2}{|c|}{ HM } & \multicolumn{2}{|c|}{ YI } & \multicolumn{2}{|c|}{ PI } \\
\hline FLIP 03-71C & 0.00071 & D & 1119.9 & B & 1085.9 & B & 1.057 & $B C$ & 220371 & A \\
\hline FLIP 03-64C & 0.00080 & $\mathrm{BCD}$ & 1167.7 & B & 1036.3 & B & 0.859 & D & 91997 & $B C$ \\
\hline FLIP 98-106C & 0.00095 & A & 1454.5 & A & 1361.3 & A & 1.229 & A & 27259 & $\mathrm{C}$ \\
\hline FLIP 00-40C & 0.00069 & D & 1072.5 & B & 1011.2 & B & 0.920 & $C D$ & 206476 & A \\
\hline FLIP 99-66C & 0.00074 & $C D$ & 1114.6 & B & 1027.0 & B & 0.895 & D & 141751 & $A B$ \\
\hline Arman & 0.00084 & $A B C$ & 1219.3 & B & 1084.6 & B & 0.901 & D & 69929 & $B C$ \\
\hline Azad & 0.00090 & $A B$ & 1380.0 & A & 1281.7 & A & 1.137 & $A B$ & 38403 & $\mathrm{C}$ \\
\hline Cultivar & \multicolumn{2}{|c|}{ YSI } & \multicolumn{2}{|c|}{ RR } & \multicolumn{2}{|c|}{$\mathrm{K}_{1} \mathrm{STI}$} & \multicolumn{2}{|c|}{$\mathrm{K}_{2} \mathrm{STI}$} & & \\
\hline FLIP 03-71C & 0.607 & A & 0.393 & C & 0.00044 & D & 0.00079 & B & & \\
\hline FLIP 03-64C & 0.371 & C & 0.629 & A & 0.00094 & $A B C$ & 0.00061 & B & & \\
\hline FLIP 98-106C & 0.491 & B & 0.509 & B & 0.00129 & A & 0.00143 & A & & \\
\hline FLIP 00-40C & 0.500 & B & 0.500 & B & 0.00050 & $C D$ & 0.00062 & B & & \\
\hline FLIP 99-66C & 0.441 & $B C$ & 0.559 & $A B$ & 0.00064 & $B C D$ & 0.00060 & B & & \\
\hline Arman & 0.373 & C & 0.627 & A & 0.00105 & $A B$ & 0.00071 & B & & \\
\hline Azad & 0.466 & B & 0.534 & B & 0.00116 & $A$ & 0.00117 & A & & \\
\hline
\end{tabular}


and finding such a genotype is good chance for plant breeders. Therefore, the genotypes FLIP 98-106C and Azad are good candidates for commercial recommendation to farmers in both rainfed and irrigated regions.

Based on the SSI, the genotypes FLIP 03-64C, FLIP 98-106C, FLIP 99-66C, Arman and Azad were identified as drought tolerance genotypes in stressed condition, while the genotypes FLIP 03-71C and FLIP 00-40C displayed the lowest amount of SSI (Table 2). According to the MP, the genotypes FLIP 98-106C and Azad were found drought tolerance genotypes in stressed condition, and the genotypes FLIP 03-71C, FLIP 03-64C, FLIP 00-40C and FLIP 99-66C were identified as drought susceptible ones in stressed condition. The other remained genotypes were identified as semi-tolerance or semi-sensitive to drought stress (Table 2). Based on the TOL, the genotypes FLIP 03-64C, FLIP 98-106C, FLIP 99-66C, Arman and Azad were identified as drought tolerance genotypes in stressed condition, while the genotypes FLIP 03-71C and FLIP 00-40C showed the lowest amount of TOL (Table 2). The genotype FLIP 00-40C was identified as semi-tolerance or semi-sensitive to drought stress conditions (Table 2).

According to the stress tolerance index (STI), the genotypes FLIP 98-106C, Arman and Azad were identified as drought tolerance genotypes, while the genotypes FLIP 03-71C, FLIP 03-64C, FLIP 00-40C and FLIP 99-66C showed the lowest amount of STI (Table 2). Based on the GMP, the genotypes FLIP 98-106C and Azad were identified as drought tolerance genotypes in stressed condition, while the other remained genotypes displayed the lowest amount of GMP (Table 2). Mevlut and Sait (2011) showed that genotypes with high STI values usually have high difference in yield in two different humidity conditions. They reported relatively similar ranks for the genotypes observed by GMP and MP parameters as well as STI, which suggests that these three parameters are equal for screening drought tolerant genotypes. According to the harmonic mean (HM), the genotypes FLIP 98-106C and Azad were identified as drought tolerance genotypes, while the other remained genotypes showed the lowest amount of GMP (Table 2). The results of both GMP and HM indices were completely similar. It seems that this similarity is due to nature of their calculating formulas and so it is logical to use one of them in future studies.

Based on the YI index, the genotypes FLIP 98-106C and Azad were identified as drought susceptible genotypes, while the genotypes FLIP 03-64C, FLIP 00-40C, FLIP 99-66C and Arman showed the lowest amount of $\mathrm{YI}$ and were drought tolerance genotypes (Table 2). According to the PI index, the genotypes FLIP 03-71C, FLIP 00-40C and FLIP 99-66C were identified as drought susceptible genotypes, while the genotypes FLIP 03-64C, FLIP 98-106C and Arman showed the lowest amount of PI and were drought tolerance genotypes (Table 2). According to the YSI index, the genotype FLIP 03-71C was identified as drought tolerance genotype, while the genotypes FLIP 03-64C, FLIP 99-66C and Arman showed the lowest amount of YSI as drought tolerance genotype (Table 2).

Based on the RR index, the genotypes FLIP 03-64C, FLIP 99-66C and Arman were identified as drought tolerance genotypes in stressed condition, while the genotype FLIP 03-71C displayed the lowest amount of RR (Table 2). According to the $\mathrm{K}_{1} \mathrm{STI}$ index, the genotypes FLIP 03-64C, FLIP 98-106C, Azad and Arman were identified as drought tolerance genotypes in stressed condition, while the genotypes FLIP 03-71C, FLIP 00-40C and FLIP 99-66C showed the lowest amount of $\mathrm{K}_{1} \mathrm{STI}$ (Table 2). Based on the $\mathrm{K}_{2} \mathrm{STI}$ index, the genotypes FLIP 98-106C and Azad were identified as drought tolerance genotypes in stressed condition, while the other remained genotypes showed the lowest amount of $\mathrm{K}_{2} \mathrm{STI}$ (Table 2). Ilker et al. (2011) reported that STI-related indices $\left(\mathrm{K}_{1} \mathrm{STI}\right.$ and $\mathrm{K}_{2} \mathrm{STI}$ ) are convenient parameters to select high-yielding genotypes in both stress and non-stress conditions, whereas relative decrease is observed in yield.

The ranks of the chickpea according to each one of the drought tolerance indices are given in Table 3. Regarding this table, the genotype FLIP 98-106C following to the cultivar Azad were the most favourable genotypes based on the most of the drought tolerance indices. According to the above ranks, spearman rank correlations were computed (Table 4). The YP showed positive correlation with SSI, MP, TOL, STI, GMP, HM, PI and $\mathrm{K}_{1} \mathrm{STI}$, while the $Y S$ indicated positive correlation with the $\mathrm{HM}, \mathrm{YI}, \mathrm{YSI}, \mathrm{RR}$ and $\mathrm{K}_{2} \mathrm{STI}$ indices (Table 4). Positive correlations among the MP, GMP and YP indices (Toorchi et al., 2012) and positive correlations among the GMP, MP and STI indices (Dehghani et al., 2009) were reported in canola. The SSI had positive association with MP, TOL, STI, PI and $\mathrm{K}_{1} \mathrm{STI}$ but had negative correlation with the YSI and RR indices. Similarly, Ehdaie and Shakiba (1996) found no correlation between stress susceptibility index and yield under optimum condition. The MP index showed positive correlation with TOL, STI, GMP, HM, PI, $\mathrm{K}_{1} \mathrm{STI}$ and $\mathrm{K}_{2} \mathrm{STI}$ (Table 4). The TOL index indicated positive

Table 3 Ranks of seven chickpea genotypes based on YP, YS and twelve drought resistance indices

\begin{tabular}{|l||c|c|c|c|c|c|c|c|c|c|c|c|c|c|}
\hline Genotype & YP & YS & SSI & MP & TOL & STI & GMP & HM & YI & PI & YSI & RR & $\mathbf{K}_{\mathbf{1}}$ STI & $\mathbf{K}_{\mathbf{2}}$ STI \\
\hline \hline FLIP 03-71C & 7 & 3 & 7 & 6 & 7 & 6 & 5 & 3 & 3 & 7 & 1 & 1 & 7 & 3 \\
\hline FLIP 03-64C & 4 & 7 & 2 & 4 & 2 & 4 & 4 & 5 & 7 & 4 & 7 & 7 & 4 & 6 \\
\hline FLIP 98-106C & 1 & 1 & 4 & 1 & 4 & 1 & 1 & 1 & 1 & 1 & 3 & 3 & 1 & 1 \\
\hline FLIP 00-40C & 6 & 4 & 6 & 7 & 6 & 7 & 7 & 7 & 4 & 6 & 2 & 2 & 6 & 5 \\
\hline FLIP 99-66C & 5 & 6 & 5 & 5 & 5 & 5 & 6 & 6 & 6 & 5 & 5 & 5 & 5 & 7 \\
\hline Arman & 3 & 5 & 1 & 3 & 1 & 3 & 3 & 4 & 5 & 3 & 6 & 6 & 3 & 4 \\
\hline Azad & 2 & 2 & 3 & 2 & 3 & 2 & 2 & 2 & 2 & 2 & 4 & 4 & 2 & 2 \\
\hline
\end{tabular}


Table 4 Spearman rank correlation coefficients of $Y P, Y S$ and twelve drought resistance indices for the seven chickpea genotypes

\begin{tabular}{|l||c|c|c|c|c|c|c|c|c|c|c|c|c|}
\hline & YP & YS & SSI & MP & TOL & STI & GMP & HM & YI & PI & YSI & RR & K STI \\
\hline \hline YS & $0.39 *$ & & & & & & & & & & & & \\
\hline SSI & 0.68 & -0.29 & & & & & & & & & & \\
\hline MP & 0.96 & 0.43 & 0.64 & & & & & & & & & & \\
\hline TOL & 0.68 & -0.29 & 1.00 & 0.64 & & & & & & & & & \\
\hline STI & 0.96 & 0.43 & 0.64 & 1.00 & 0.64 & & & & & & & & \\
\hline GMP & 0.89 & 0.54 & 0.57 & 0.96 & 0.57 & 0.96 & & & & & & & \\
\hline HM & 0.64 & 0.75 & 0.18 & 0.79 & 0.18 & 0.79 & 0.89 & & & & & & \\
\hline YI & 0.39 & 1.00 & -0.29 & 0.43 & -0.29 & 0.43 & 0.54 & 0.75 & & & & & \\
\hline PI & 1.00 & 0.39 & 0.68 & 0.96 & 0.68 & 0.96 & 0.89 & 0.64 & 0.39 & & & & \\
\hline YSI & -0.39 & 0.68 & -0.86 & -0.36 & -0.86 & -0.36 & -0.21 & 0.18 & 0.68 & -0.39 & & & \\
\hline RR & -0.39 & 0.68 & -0.86 & -0.36 & -0.86 & -0.36 & -0.21 & 0.18 & 0.68 & -0.39 & 1.00 & & \\
\hline K STI & 1.00 & 0.39 & 0.68 & 0.96 & 0.68 & 0.96 & 0.89 & 0.64 & 0.39 & 1.00 & -0.39 & -0.39 & \\
\hline K STI & 0.54 & 0.93 & 0.00 & 0.61 & 0.00 & 0.61 & 0.75 & 0.89 & 0.93 & 0.54 & 0.46 & 0.46 & 0.54 \\
\hline
\end{tabular}

correlation with STI, PI and $\mathrm{K}_{1} \mathrm{STI}$ while showed negative correlation with the YSI and RR indices. The STI had positive correlation with GMP, HM, PI, K STI and $\mathrm{K}_{2} \mathrm{STI}$, while GMP had positive correlation with $\mathrm{HM}, \mathrm{PI}, \mathrm{K}_{1} \mathrm{STI}$ and $\mathrm{K}_{2} \mathrm{STI}$ (Table 4). The $\mathrm{HM}$ indicated positive correlation with $\mathrm{YI}, \mathrm{PI}, \mathrm{K} S \mathrm{STI}$ and $\mathrm{K}_{2} \mathrm{STI}$, while the $\mathrm{YI}$ indicated positive correlation with $\mathrm{YSI}, \mathrm{RR}$ and $\mathrm{K}_{2} \mathrm{STI}$ (Table 4). The positive correlation was observed between $\mathrm{PI}$ and $\mathrm{K}_{1} \mathrm{STI}$ and between YSI and RR. In general, the observed relationships in our chickpea genotypes were consistent with those reported by Golabadi et al. (2006) in durum wheat and Khalili et al. (2012) in canola.

The relationships among drought tolerance indices are graphically displayed in a plot of two first principal components (PC1 and PC2) analysis (Fig. 1). The first and second components justified $95.46 \%$ of the variations between criteria (59.36 and $36.10 \%$ for $P C 1$ and $P C 2$, respectively). The PC1 mainly distinguishes the $\mathrm{RR}$ and $\mathrm{YSI}$ indices from the other remained indices, and the $\mathrm{PC2}$ distinguishes the SSI and TOL indices from the indices which related to each other based on the PC1 scores (Fig. 1).

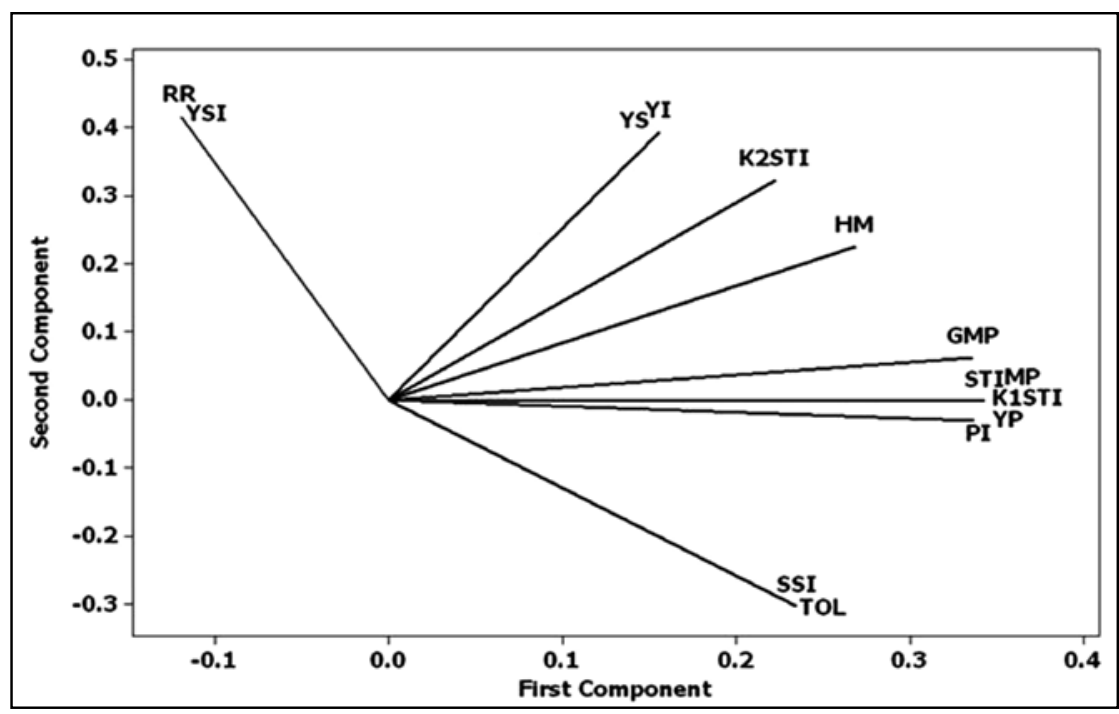

Figure 1 Plot of first two principal component axes of drought tolerance indices in chickpea genotypes

One of the interesting interpretations of this plot is that the cosine of the angle between the vectors of two indices approximates the correlation coefficient between them. The cosine of the angles does relatively translate into correlation coefficients, since the plot of principal components analysis does explain most of the variation in a data set. Therefore, it could be concluded that the GMP, MP, STI, $\mathrm{K}_{1} \mathrm{STI}, \mathrm{YP}$ and $\mathrm{PI}$ indices are positively associated with each other (Fig. 1). Also, positive associations were seen between SSI with TOL, between RR with YSI, and between $\mathrm{YI}$ with YS.

There is general agreement that new genetically improved highyielding crop genotypes are more adapted to favourable growing conditions, while conventional cultivars have more stable performance under drought stress conditions. It was interesting to note positive correlation between STI and YP indicating that STI was positively correlated with non-stressed yield. This finding suggested that some traits that contribute to yield potential may act to increase tolerance to stress and that selection for both STI and YP may counteract each other. Several studies indicated that the GMP, STI, PI and MP indices are preferred in late drought condition for selecting the most favourable genotypes (Blum, 1996; Sio-Se Mardeh et al., 2006; Akcura et al., 
2011). The HM and $\mathrm{K}_{2}$ STI could be used for screening drought tolerant high-yielding genotypes in both conditions.

The mentioned parameters under level of high to moderate stress were correlated (Akcura et al., 2011) with yield under both conditions. Also, they were able to differentiate genotypes belonging to genotypes with high-yield performance in both conditions, from the others. Akcura et al. (2011) reported when the stress was severe, SSI was to be more useful index for determining tolerant genotypes, although most of the indices could identify genotypes with high yield under both stressed and non-stressed conditions. The use of landraces has been neglected in breeding programmes because they have low-yield potential under irrigated conditions while they have out yielded the exotic material under low input conditions (Blum, 1996; Ceccarelli et al., 1998; Dencic et al., 2000). The most effective way to improve the crops' performance in unfavourable environments is to use locally adapted germplasms and select them for target regions. Drought conditions are predominant over the years and wet years are infrequent in the most area of Iran and therefore selection should be based on the yield in the target regions. If the main propose of breeding programme is to improve yield in small stress or non-stress conditions, it may be possible to describe local adaptation to increase gains from selection (Hohls, 2001; Sio-Se Mardeh et al., 2006; Akcura et al., 2011).

In spite of selection of new tolerant genotypes, the need for modifying and introducing new technology for increasing and sustaining yield in dry land areas can hardly be overemphasized. A large part of the arid and semi arid regions of Mediterranean basin have not been absolutely touched by the Green Revolution which only boosts grain yields where sufficient water for irrigation is available. Farmers in the semi-arid environment in Northwest of Iran face some distinctive challenges. In some parts, the elevation is relatively high, making for a short growing season. Killing frosts occur late in the spring and early in the fall. In some years, low amount of rainfall comes later in the growing season than in most areas, creating another stress. The soil's relatively low organic matter and steep slopes contribute to erosion with summer storms. These regions frequently have not been attracted commercial investments in agricultural technology improvement because their farms are small and it is hard to step up productivity when low precipitation limits plant growth. It seems that conservation tillage and crop diversification can improve soil quality and increase yields. However, mechanization on small farms in the Mediterranean region is difficult because there are economies of scale when purchasing and operating farm machinery. However, governmental investment, farm machinery hire cooperative, group ownership of machinery, share cropping between farmers and small machines may be able to provide considerable advantages.

\section{Conclusions}

In conclusion, based on the plot of principal component analysis, the indices of STI, K STI, MP, GMP, and PI exhibited strong correlation with YP, while $\mathrm{YI}$ showed strong correlation with YS; therefore, YS can discriminate drought tolerant genotypes with high grain yield under stress conditions. Also, $\mathrm{K}_{2} \mathrm{STI}$ and $\mathrm{HM}$ exhibited relatively moderate association with both $Y P$ and $Y S$; thus, they can discriminate drought tolerant genotypes with high grain yield at the same manner under stress and non-stress conditions. It is further concluded that the genotype FLIP 98-106C and the cultivar Azad have uniform superiority under both stress and irrigated conditions. The genotype FLIP 98-106C G5 (2095.3 kg.ha-1 at non-stressed and $1015.2 \mathrm{~kg}^{-h^{-1}}$ at stressed conditions) besides the cultivar Azad (2033.4 kg.ha-1 at non-stressed and $939.5 \mathrm{~kg} . \mathrm{ha}^{-1}$ at stressed conditions) were found to be the most favourable genotypes and are thus recommended for farmers in arid and semi-arid areas of Iran. However, these suitable genotypes need the use of new tillage technologies for better managing the soil moisture content in chickpea producing regions especially in the semi-arid areas.

\section{Acknowledgement}

The authors thank the Dryland Agricultural Research Institute (DARI) and for making available the plant materials.

\section{References}

AKCURA, M. - PARTIGOC, F. - KAYA, Y. 2011. Evaluating of drought stress tolerance based on selection indices in Turkish bread wheat landraces. In The Journal of Animal and Plant Sciences, 2011, no. 21, pp. 700-709.

BLUM, A. 1996. Crop responses to drought and the interpretation of adaptation. In Plant Growth Regulation, 1996, no. 20, pp. 135-148.

BOUSLAMA, M. - SCHAPAUGH, W. T. 1984. Stress tolerance in soybean. Part 1: evaluation of three screening techniques for heat and drought tolerance. In Crop Science, 1984, no. 24, pp. 933-937.

CECCARELLI, S. - GRANDO, S. - IMPIGLIA, A. 1998. Choice of selection strategy in breeding barley for stress environments. In Euphytica, 1998, no. 103, pp. 307-138.

CLARKE, J. M. - DEPAUW, R. M. - TOWNLEY-SMITH, T. F. 1992. Evaluation of methods for quantification of drought tolerance in wheat. In Crop Science, 1992, no. 32, pp. 723-728.

DEHGHANI, H. - MALEKSHHI, F. - ALIZADEH, B. 2009. A study of drought tolerance indices in canola (Brassica napus L.) genotypes. In Journal of Science and Technology of Agriculture and Natural Resources, 2009, no. 13, pp. 77-90.

DENCIC, S. - KASTORI, R. - KOBILJSKI, B. - DUGGAN, B. 2000. Evaluation of grain yield and its components in wheat cultivars and landraces under near optimal and drought conditions. In Euphytica, 2000, no. 113, pp. 43-52.

EHDAIE, B. - SHAKIBA, M. R. 1996. Relationship of inter node specific weight and water-soluble carbohydrates in wheat. In Cereal Research Communication, 1996, no. 24, pp. 61-67.

GOLABADI, M.A. - ARZANI, S.A. - MAIBODY, M. 2006. Assessment of drought tolerance in segregating populations in durum wheat. In African Journal of Agricultural Research, 2006, no. 22, pp. 62-171.

FAO. 2011. FAO STAT data. Food and Agriculture Organization of the United Nations. http://faostat.fao.org/.

FERNANDEZ, G.C.J. 1992. Effective selection criteria for assessing stress tolerance. In Kuo, C.G. (Ed.), Proceedings of the International Symposium on Adaptation of Vegetables and Other Food Crops in Temperature and Water Stress, Publication, Tainan, Taiwan, 1992.

FISCHER, R.A. - MAURER, R. 1978. Drought resistance in spring wheat cultivars. Part 1: grain yield response. In Australian Journal of Agriculture Research, 1978, no. 29, pp. 897-912. 
GAVUZZI, P. - RIZZA, F. - PALUMBO, M. - CAMPALINE, R.G. RICCIARDI, G.L. - BORGHI, B. 1997. Evaluation of field and laboratory predictors of drought and heat tolerance in winter cereals. In Canadian Journal of Plant Science, 1997, no. 77, pp. 523-531.

GOLABADI, M. - ARZANI, A. - MIRMOHAMMADI-MAIBODY, S.A.M. 2006. Assessment of drought tolerance in segregating populations in durum wheat. In African Journal of Agriculture Research, 2006, no. 1, pp. 162-171.

HOHLS, T. 2001. Conditions under which selection for mean productivity, tolerance to environmental stress, or stability should be used to improve yield across a range of contrasting environments. In Euphytica, 2001, no. 120, pp. 235-245.

ILKER, E. - TATAR, O. - AYKUT-TONK, F. - TOSUN, M. - TURK, J. 2011. Determination of tolerance level of some wheat genotypes to postanthesis drought. In Turkish Journal of Field Crops, 2011, no. 16, pp. 59-63.

KHALILI, M. - NAGHAVI, M.R. - POUR ABOUGHADAREH, A.R. TALEBZADEH, S.J. 2012. Evaluating of drought stress tolerance based on selection indices in spring canola cultivars (Brassica napus L.). In Journal of Agricultural Science, 2012, no. 4, pp. 78-85.

LIN, C.S. - BINNS, M.R. 1988. A superiority measure of cultivar performance for cultivar $\times$ location data. In Canadian Journal of Plant Science, 1988 , no. 68, pp. 193-198.

MEVLUT, A. - SAIT, C. 2011. Evaluation of drought tolerance indices for selection of Turkish oat (Avena sativa L.) landraces under various environmental conditions. In Zemdirbyster, 2011, no. 98, pp. 157-166.

MOHAMMADI, R. - ARMION, M. - KAHRIZI, D. - AMRI, A. 2010. Efficiency of screening techniques for evaluating durum wheat genotypes under mild drought conditions. In International Journal Plant Production, 2010, no. 4, pp. 11-24.

OZVEREN-YUCEL, D. - ANLARSAL, E.A. - YUCEL, C. 2006. Genetic variability, correlation and path analysis of yield, and yield components in chickpea (Cicer arietinum L.). In Turkish Journal of Agriculture and Forestry, 2006, no. 30, pp. 183-188.

RAMIREZ, P. - KELLY, J.D. 1998. Traits related to drought resistance in common bean. In Euphytica, 1998, no. 99, pp. 127-136.

RICHARDS, R.A. - REBETZKE, G.J. - CONDON, A.G. - HERWAARDEN, A.F. 2002. Breeding opportunities for increasing the efficiency of water use and crop yield in temperate cereals. In Crop Science, 2002, no. 42, pp. 111-121.
ROSIELLE, A.A. - HAMBLIN, J. 1981. Theoretical aspects of selection for yield in stress and non-stress environments. In Crop Science, 1981, no. 21, pp. 943-946.

SABAGHPOUR, S.H. - MAHMODI, A. - SAEED, A. - KAMEL, M. MALHOTRA, R.S. 2006. Study on chickpea drought tolerance lines under dryland condition of Iran. In Indian Journal of Crop Science, 2006, no. 1, pp. 70-73.

SADIKI, M. 2006. Diversity of Moroccan local faba bean landraces for reaction to drought stress. In Enhancing the use of crop genetic diversity to manage abiotic stress in agricultural production systems (Editors, JARVIS, D. - MAR, I. - SEARS, L.). 23-27 May 2005, Budapest, Hungary. IPGRI (International Plant Genetic Resources Institute), Rome, Italy.

SAS Institute, Inc. 1996. SAS/STAT user's guide. Version 6.12. SAS Institute Inc., Cary, NC, USA.

SIO-SE MARDEH, A. - AHMADI, A. - POUSTINI, K. - Mohammadi, V. 2006. Evaluation of drought resistance indices under various environmental conditions. In Field Crops Research, 2006, no. 98, pp. 222-229.

TOKER, C. - CAGIRGAN, M.I. 1998. Assessment of response to drought stress of chickpea (Cicer arietinum L.) lines under rainfed conditions. In Turkish Journal of Agriculture and Forestry, 1998, no. 22, pp. 615-622.

TOORCHI, M. - NADERI, R. - KANBAR, A. - SHAKIBA, M.R. 2012. Response of spring canola cultivars to sodium chloride stress. In Annals of Biological Research, no. 2, pp. 312-322.

ZDEMUR, S. - KARADAVUT, U. 2003. Comparison of the performance of autumn and spring sowing of chickpeas in a temperate region. In Turkish Journal of Agriculture and Forestry, no. 27, pp. 345-352.

\section{Contact address:}

*Mohsen Janmohammadi, University of Maragheh, Agriculture College, Department of Agronomy and Plant Breeding, East Azerbaijan, Iran, e-mail: mjanmohammadi@ maragheh.ac.ir 